\title{
Organic Matter Characterization in Shales: A Systematic Empirical Protocol
}

\author{
Kultaransingh Hooghan ${ }^{1}$, Lori Hathon ${ }^{2}$, Mike Dixon ${ }^{1}$, Mike Myers ${ }^{2}$ \\ 1. Weatherford Laboratories, Houston, TX; \\ 2. University of Houston, Petroleum Engineering Department, Houston, TX
}

Increased economic interest in shale oil and gas has prompted new exploration in shale reservoirs. This has catalyzed new research into how storage and delivery work in tight gas sands and shales. Focusing on the organic matter (OM) present in the shales we have developed a process enabling us to study changes in $\mathrm{OM}$ before and after heating and extraction using various solvents in the laboratory. We compare the changes in $\mathrm{OM}$ during laboratory heating and extraction to observations made on subsurface samples at varying maturity. The OM was characterized using a Field Emission Scanning Electron Microscope (FE-SEM) at various imaging voltages as deemed necessary.

Sample material for this study is from the Eagle Ford Formation. Thermal maturity of the samples ranges from $0.5-1.2 \% \mathrm{R}_{\mathrm{O}}$ (percent vitrinite reflectance in oil). We refer to these as low (Ro 0.5\%), medium (Ro $\sim 0.9 \%$ ), and high maturity (Ro 1.2\%) samples, respectively. One additional sample from the Mancos Formation of unknown maturity was also examined. This sample was included in order to document the differences between clay- and carbonate-rich mudrocks.

Facing surfaces of end trims from 1" diameter horizontal core plugs were used for Thin Section (TS) preparation, and subjected to Broad Beam Argon Ion Milling (AIM) for SEM analysis. Imaging and image analysis of these portions of the sample were used to put the samples for retort into context. The remainder of the sample was crushed for standard Shale Rock Properties tests (e.g TOC, etc.) and for Xray Diffraction analysis. Two of the largest pieces of the crushed material, labeled A, and B, were subjected to AIM for pre- and post-retort SEM imaging. These samples were imaged in detail in their native state using a Helios Small Dual Beam (SDB) 650 (FEI/Thermo FISHER corporation). Imaging included a low resolution image mosaic of the entire milled surface, and high magnification images of selected areas. The pre-retort imaging procedure was followed post-retort, to accurately document results of the heating/extraction. This ensured a systematic and reproducible workflow.

Pyrolysis experiments are typically carried out by ramping temperature from ambient to $\sim 650^{\circ} \mathrm{C}$. In order to capture the early maturation phase in the laboratory, our initial retorts were carried out at $350^{\circ} \mathrm{C}$, for 15 hours. Figures $1 \& 2$ show a given location on a low maturity sample, native state and post $350^{\circ} \mathrm{C}$ retort. The retort image shows a complete removal of the organic material. Subsequent to this finding, retort temperatures were lowered to $300^{\circ} \mathrm{C}$, and $325^{\circ} \mathrm{C}$ for the remaining samples. In low maturity samples, a significant shrinkage of marine sedimentary organic material was observed upon heating to $300^{\circ} \mathrm{C}$ (Figures 3 and 4). Terrestrial organic material remained stable over the entire range of heating experiments. Pre-retort imaging of the middle and high maturity samples showed that volumes of marine sedimentary organic material had been significantly reduced during natural maturation. Only about $10-20 \%$ of the primary sedimentary OM observed in low maturity samples is retained in medium and high maturity native state samples. This is similar to observations of wholesale removal of marine OM made during the laboratory experiments, but in contrast to "conventional wisdom" which holds that approximately $50 \%$ of marine type II kerogen is refractory or inert (e.g. Hunt, 1996). In the medium maturity sample, complete removal of pore filling bitumen occurred at $300^{\circ} \mathrm{C}$. In contrast to the low 
maturity sample, residual sedimentary $\mathrm{OM}$ (both marine and terrestrial) was stable during the retort to both $300^{\circ} \mathrm{C}$ and $325^{\circ} \mathrm{C}$. In the high maturity sample (bitumen converted to pyrobitumen during natural maturation) residual sedimentary OM and pyrobitumen with typical "organic matter" hosted pores were stable during the retort experiments [1] [2].

\section{References:}

[1] Protocol for finalizing locations for FIB/SEM cubes on shale samples: general guidelines with upscaling in mind, Kultaransingh Hooghan, Michael Dixon, Weatherford Laboratories, Houston, TX; Lori Hathon, Shell E \& P Houston, TX, URTeC, *1922784, Denver, August 2014, Denver, CO USA. [2] Use of Digital Imaging for Improved Evaluation of Unconventional Reservoirs, Kultaransingh Hooghan, et al. SPE Reservoir Characterization and Simulation conference and Exhibition, Abu Dhabi, 2013

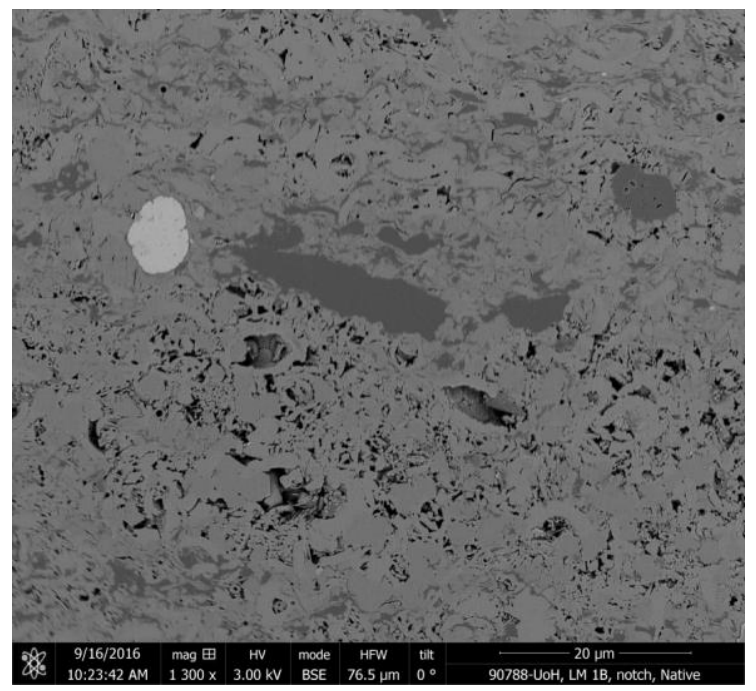

Figure 1. Low Maturity 1B, Native state. Red Arrows indicate marine OM.

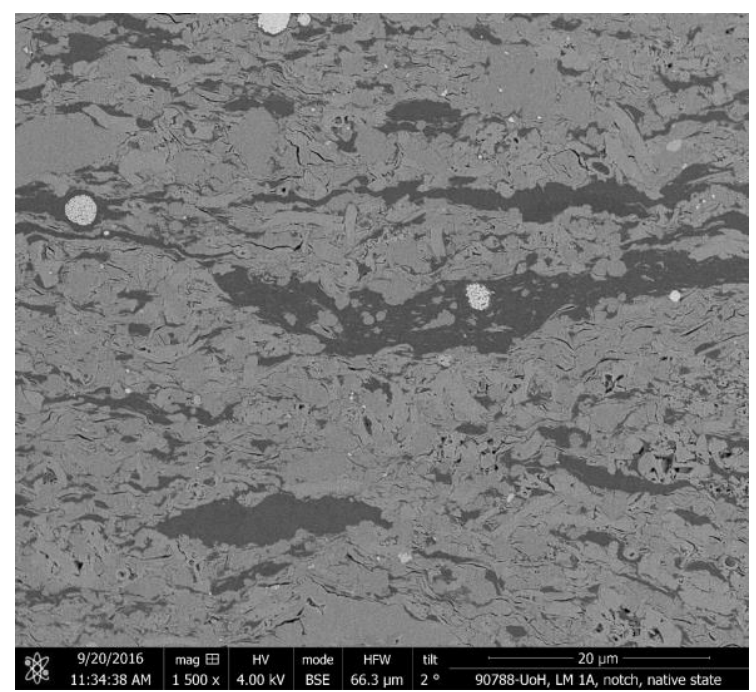

Figure 3. Low Maturity 1A, Native state. Bedding plane parallel marine OM $\sim 10 \%$.

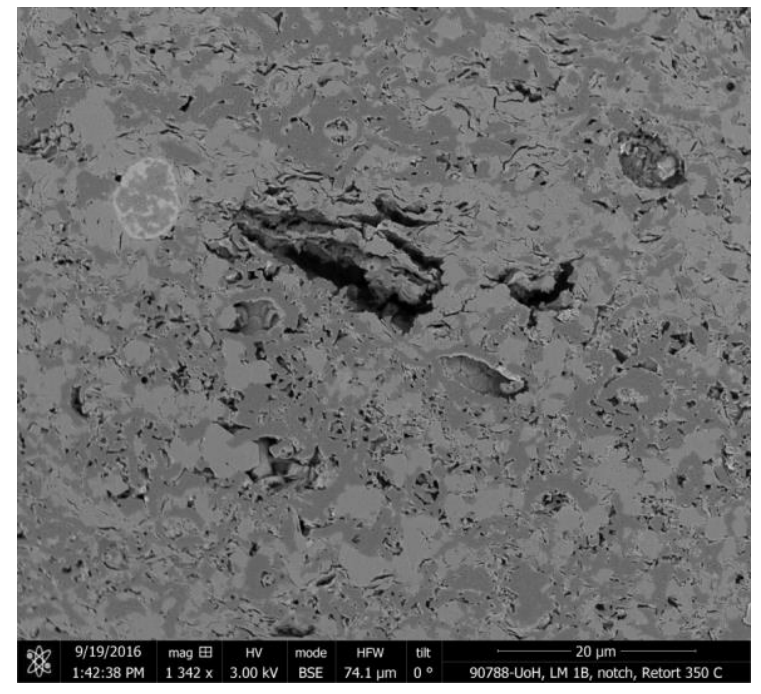

Figure 2. Low Maturity $1 \mathrm{~B}$, Post $350^{\circ} \mathrm{c}$ retort Red arrows indicate removal of marine OM.

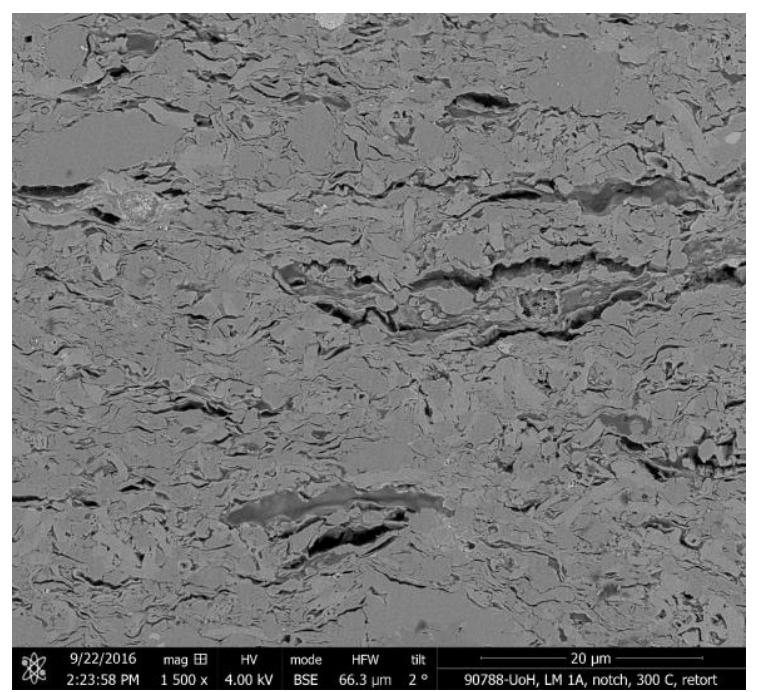

Figure 4. Low Maturity 1A, Post 300C Retort Substantial shrinkage of marine OM. 